\title{
Postpartum hemorrhage: incidence, risk factors, and outcomes in a low-resource setting
}

\author{
This article was published in the following Dove Press journal: \\ International Journal of Women's Health \\ 2 November 2016 \\ Number of times this article has been viewed
}

\author{
Solwayo Ngwenya ${ }^{1-3}$ \\ 'Department of Obstetrics and \\ Gynaecology, Mpilo Central Hospital, \\ Bulawayo, Zimbabwe; ${ }^{2}$ Royal Women's \\ Clinic, Bulawayo, Zimbabwe; ${ }^{3}$ Medical \\ School, National University of Science \\ and Technology, Matabeleland, \\ Zimbabwe
}

Background: Primary postpartum hemorrhage (PPH) is defined as blood loss from the genital tract of $500 \mathrm{~mL}$ or more following a normal vaginal delivery (NVD) or 1,000 $\mathrm{mL}$ or more following a cesarean section within 24 hours of birth. PPH contributes significantly to maternal morbidity and mortality worldwide. Women can rapidly hemorrhage and die soon after giving birth. It can be a devastating outcome to many young families. Women giving birth in low-resource settings are at a higher risk of death than their counterparts in resource-rich environments. PPH is a leading cause of maternal deaths globally, contributing to a quarter of the deaths annually. Aims: This study aims 1) to document the incidence, risk factors, and causes of PPH in a lowresource setting and 2) to document the maternal outcomes of PPH in low-resource setting.

Methods: This was a retrospective descriptive cohort study carried out at Mpilo Central Hospital, a tertiary referral government hospital in a low-resource setting in Bulawayo, Zimbabwe. Data were obtained from the labor ward birth registers for patients who had a diagnosis of PPH during the period from January 1, 2016 to June 30, 2016. The case notes were retrieved and the demographic, clinical, and outcome data were gathered. Blood loss was estimated postdelivery by the attending clinician - either a midwife or a doctor. At this maternity unit, blood loss is not measured but estimated owing to prevailing resource constraints. The SPSS Version 21 statistical tool was used to calculate the mean and standard deviation (SD) values. Simple statistical tests were used on absolute numbers to calculate percentages.

Results: There were 4,567 deliveries at the institution during the period from January 1, 2016 to June 30, 2016. There were 74 cases of PPH during the study period. The incidence of primary PPH was $1.6 \%$. The mean age was 27.7 years ( $\mathrm{SD} \pm 6.9$ ), mean gestational age was 38.6 weeks gestation ( $\mathrm{SD} \pm 2.2$ ), and mean birth weight was $3.16 \mathrm{~kg}(\mathrm{SD} \pm 0.65)$ for the studied group of patients. Three-quarters (75.7\%) of the cases had NVD. The majority of the cases (77.0\%) had an identifiable risk factor for developing primary PPH. The most identifiable risk factor for primary PPH was pregnancy-induced hypertension followed by prolonged labor. Uterine atony was the most common cause of postpartum hemorrhage (82.4\%). The women who delivered by NVD, who were diagnosed with a PPH, and who lost an estimated $500-1,000 \mathrm{~mL}$ of blood were $73.2 \% ; 25 \%$ lost $1,000-1,500 \mathrm{~mL}$ of blood, and $1.8 \%$ lost more than $1,500 \mathrm{~mL}$ of blood. The women who delivered by lower-segment cesarean section, who were diagnosed with a PPH, and who lost an estimated $1,000-1,500 \mathrm{~mL}$ of blood were $77.8 \%$, and $22.2 \%$ bled an estimated $1,500 \mathrm{~mL}$ of blood or more. The majority of the cases of primary PPH (94.6\%) survived the condition and 5.4\% died.

Conclusion: The incidence of PPH at Mpilo Central Hospital was 1.6\% during the study period, lower than that reported elsewhere in similar setting in the literature. This study, therefore, is important as it documents for the first time for this maternity unit and for a Zimbabwean setting, the incidence of one of the most important causes of global maternal deaths. Future studies should involve the effect on maternal outcomes of PPH following widespread introduction of misoprostol therapy into practice. This data can help in mobilizing global efforts to improve women's health.

Keywords: causes, uterotonics, avoidable deaths, maternal outcomes, low-resource settings 


\section{Introduction}

An estimated 2,87,000 maternal deaths occurred worldwide in $2010 .{ }^{1}$ The major causes were primary postpartum hemorrhage (PPH), hypertensive disorders, and sepsis. PPH is defined as blood loss from the genital tract of $500 \mathrm{~mL}$ or more following a normal vaginal delivery (NVD) or $1,000 \mathrm{~mL}$ or more following a cesarean section within 24 hours of delivery. Globally, it is the leading cause of maternal deaths and is responsible for $25 \%$ of deaths annually. ${ }^{2,3}$ It is the leading cause of maternal mortality in sub-Saharan Africa. ${ }^{4,5}$ The region has poor health care facilities that are inadequate and inaccessible due to financial constraints. Most of the maternal deaths in this region are avoidable. Women giving birth in these regions face a far greater risk of dying in childbirth than their counterparts in resource-rich regions.

The incidence of PPH for this unit or that for Zimbabwe has not been documented before in the literature. The incidence of PPH in a low-resource tertiary hospital in Nigeria was found to be $4.5 \%,{ }^{6}$ in Uganda, (an African country) it was $9 \%,{ }^{7}$ and it was $6.4 \%$ in the high-resource country of the Netherlands in Europe. ${ }^{8}$

\section{Methods}

This was a retrospective descriptive cohort study carried out at Mpilo Central Hospital, a tertiary referral government hospital in a low-resource setting in Bulawayo, Zimbabwe. There is no formal ethics committee at the hospital, but a waiver for all nonintervention studies was obtained from the Hospital Executive. No ethical issues arose during this study and no consent was necessary as the study was a retrospective one and all the data were anonymous. Data were obtained from the labor ward birth registers for patients who had a diagnosis of PPH during the period from January 1, 2016 to June 30, 2016. The case notes were retrieved and the demographic, clinical, and outcome data were gathered. Blood loss was estimated postdelivery by the attending clinician - either a midwife or doctor. At the unit, blood loss is not measured but estimated owing to prevailing resource constraints. The SPSS Version 21 (IBM Corp., Armonk, NY, USA) statistical tool was used to calculate the mean and standard deviation (SD) figures. Simple statistical tests were used on absolute numbers to calculate percentages.

\section{Results}

There were 4,567 deliveries at the institution during the period from January 1, 2016 to June 30, 2016. There were 74 cases of PPH. The incidence of PPH was $1.6 \%$ at Mpilo Central Hospital. The mean age was 27.7 years (SD \pm 6.9 ), mean gestational age was 38.6 weeks gestation ( $\mathrm{SD} \pm 2.2$ ), and mean birth weight was $3.16 \mathrm{~kg}(\mathrm{SD} \pm 0.65)$ for the studied group of patients.

Tables 1-7 capture most of the results of the study. Threequarters $(75.7 \%)$ of the cases had NVD. The majority of the cases $(77.0 \%)$ had an identifiable risk factor for developing PPH. The most identifiable risk factor for primary PPH was pregnancy-induced hypertension $(33.3 \%)$ followed by prolonged labor (17.5\%) and large for gestational age (15.8\%). Uterine atony was the most common cause of postpartum hemorrhage $(82.4 \%)$ followed by perineal trauma $(13.5 \%)$. The women who delivered by NVD, who were diagnosed with a PPH, and who lost an estimated 500-1,000 $\mathrm{mL}$ of blood were $73.2 \% ; 25 \%$ lost 1,000-1,500 mL of blood; and $1.8 \%$ lost more than $1,500 \mathrm{~mL}$. The women who delivered by lower-segment cesarean section, who were diagnosed with a PPH, and who lost an estimated 1,000-1,500 mL of blood loss were $77.8 \%$, and $22.2 \%$ bled an estimated $1,500 \mathrm{~mL}$ of blood or more. The majority of the cases of PPH $(94.6 \%)$ survived the condition and $5.4 \%$ died.

\section{Discussion}

The incidence of PPH at Mpilo Central Hospital, Bulawayo, Zimbabwe was $1.6 \%$. This is lower than figures reported from a tertiary center in Nigeria in a similar low-resource setting in sub-Saharan Africa where the incidence was found to be $4.5 \%$. This data is crucial as it focuses on which areas to target most so that global efforts aimed at reducing maternal deaths are fully utilized. Maternal deaths are huge global health concern.

This study shows that the majority of the cases of PPH at Mpilo Central Hospital had an identifiable risk factor for developing PPH. The most identifiable risk factor for PPH was pregnancy-induced hypertension followed by prolonged labor. The patients with combined risk factors were included in the "others/combined" group as they constituted a minority. Nearly 1 in 4 had no identifiable risk factor for PPH. This information shows that the health personnel should always be well prepared to act swiftly to prevent maternal deaths, as the condition may develop even where there are no identifiable risk factors.

Table I Mode of delivery

\begin{tabular}{ll}
\hline Mode & $\mathbf{N}=\mathbf{7 4}(\%)$ \\
\hline NVD & $56(75.7)$ \\
LSCS & $18(24.3)$ \\
Total & $74(100)$ \\
\hline Abbreviations: NVD,
\end{tabular}

Abbreviations: NVD, normal vaginal delivery; LSCS, lower-segment cesarean section. 
Table 2 Risk factors

\begin{tabular}{ll}
\hline Occurance & $\mathbf{N}=\mathbf{7 4}$ (\%) \\
\hline Present & $57(77.0)$ \\
Absent & $17(23.0)$ \\
Total & $74(100)$ \\
\hline
\end{tabular}

Table 3 Risk factors in mode of delivery

\begin{tabular}{ll}
\hline Mode of delivery & $\mathbf{N}=\mathbf{5 7}(\%)$ \\
\hline NVD & $4 I(72.0)$ \\
LSCS & $16(28.0)$ \\
Total & $57(100)$ \\
\hline
\end{tabular}

Abbreviations: NVD, normal vaginal delivery; LSCS, lower-segment cesarean section.

Table 4 Risk factors frequency

\begin{tabular}{ll}
\hline Risk factor & $\mathbf{N = 5 7}$ (\%) \\
\hline PIH/Preeclampsia & $19(33.3)$ \\
Prolonged labor & $10(17.5)$ \\
Large for gestational age & $9(15.8)$ \\
Previous LSCS & $7(12.3)$ \\
APH/IUD & $5(8.8)$ \\
Others/combined & $7(12.3)$ \\
Total & $57(100)$ \\
\hline
\end{tabular}

Abbreviations: $\mathrm{PIH}$, pregnancy-induced hypertension; LSCS, lower-segment cesarean section; APH, antepartum hemorrhage; IUD, intrauterine death.

Table 5 Causes of postpartum hemorrhage

\begin{tabular}{ll}
\hline Cause & $\mathbf{N = 7 4 ( \% )}$ \\
\hline Uterine atony & $61(82.4)$ \\
Perineal trauma & $10(13.5)$ \\
Retained placenta & $2(2.7)$ \\
Bleeding disorder & $1(1.4)$ \\
Total & $74(100)$ \\
\hline
\end{tabular}

Table 6 Estimated blood loss

\begin{tabular}{llll}
\hline Mode of delivery & $\mathbf{5 0 0 - I , 0 0 0 ~} \mathbf{m L}$ & $\mathbf{I , 0 0 0 - I , 5 0 0 ~} \mathbf{~ L L}$ & $>1,500 \mathbf{~ m L}$ \\
\hline NVD N=56 (\%) & $4 \mathrm{I}(73.2)$ & $\mathrm{I} 4(25)$ & $\mathrm{I}(1.8)$ \\
LSCS N=I8 (\%) & & $14(77.8)$ & $4(22.2)$ \\
\hline
\end{tabular}

Abbreviations: NVD, normal vaginal delivery; LSCS, lower-segment cesarean section.

Table 7 Maternal outcomes

\begin{tabular}{ll}
\hline Outcome & $\mathbf{N}=\mathbf{7 4}(\%)$ \\
\hline Survived & $70(94.6)$ \\
Died & $4(5.4)$ \\
Total & $74(100)$ \\
\hline
\end{tabular}

Uterine atony is the primary direct cause of maternal morbidity globally. ${ }^{9}$ The active management of the third stage of labor with uterotonics reduces the risk of postpartum hemorrhage. ${ }^{10}$ Oxytocin and ergometrine are the drugs widely used for this purpose. At this maternity unit, the third stage of labor is actively managed with oxytocin as the main uterotonic agent. All the cases of primary PPH diagnosed during the study period received additional uterotonic doses as treatment for PPH.

Currently, the use of oral misoprostol has been associated with significant decreases in rates of acute cases of PPH and mean blood loss. ${ }^{8,11}$ Misoprostol has been found to be an effective therapy for primary PPH and can be used after exposure to uterotonic agents. ${ }^{12}$ The other interventions that have been proposed include the antishock garment and balloon tamponade. ${ }^{13}$

In this maternity unit, there has been an introduction of regular obstetric emergency drills. There are clearly marked and regularly stocked PPH boxes to deal with such emergency cases. This could have contributed to the low incidence of PPH. The majority of cases at the unit are due to uterine atony, and hence very rapid administration of extra uterotonic doses once the condition develops appears to prevent women from losing too much blood, thereby preventing deaths (Table 6). Most of the cases of PPH seemed to be rapidly arrested soon after diagnosis, before the patients lost too much blood. No women underwent hysterectomy during the period of the study. $94.6 \%$ of those diagnosed with a PPH survived. Clinical awareness and regular obstetric drills can improve on these figures and save more lives.

This is an important study in a low-resource unit in subSaharan Africa as it documents the incidence of one of the major contributory conditions to global maternal death figures. Such data may help to inform policies to improve maternal health. This helps in decision-making and prioritization of health policies, programs, and funding to reduce maternal deaths at local, regional, and global levels. ${ }^{1}$ Multinational financial institutions could help with debt cancelation so that funds are channeled to maternal health issues.

\section{Limitations}

The limitations of the study include the fact that the diagnosis of PPH was based on estimated rather than measured blood loss methods. It is very difficult to estimate blood loss. Unfortunately in low-resource countries, this is the only available method for use. There may also be observer variations as different clinicians with differences in their grade, training, and experience made the diagnosis. 


\section{Conclusion}

The incidence of PPH at Mpilo Central Hospital was 1.6\%. The most identifiable risk factor at the unit for postpartum hemorrhage was pregnancy-induced hypertension. The most common cause of postpartum hemorrhage was uterine atony. It is very important to note that nearly a quarter of women had no identifiable risk factor for developing PPH, necessitating that the attending clinicians must always be well prepared to deal with this condition that can cost so many precious lives.

With current knowledge on the effectiveness of misoprostol, its concurrent use with uterotonics can only reduce these mortality figures. Misoprostol, being a cheaper drug, would particularly be helpful in low-resource countries. The provision of safe and effective delivery care for all women in poor countries ${ }^{14}$ remains difficult, resulting in the continuation of avoidable maternal deaths from PPH.

The prevention of PPH in low-resource countries must be prioritized $^{15}$ to prevent these unnecessary avoidable deaths. Future studies should involve the effect on maternal outcomes of postpartum hemorrhage following widespread introduction of misoprostol therapy into routine clinical practice. Chances are the world may turn a corner on these truly astonishing and appalling statistics on our young mothers dying of a preventable cause in the twenty-first century. Efforts at local, national, regional, and international levels must be taken to reduce the numbers of avoidable maternal deaths.

\section{Disclosure}

The author reports no conflicts of interest in this work.

\section{References}

1. Say L, Chou D, Gemmill A, et al. Global causes of maternal death: a WHO systematic analysis. Lancet Glob Health. 2014;2(6):e323-e333.

2. Geller SE, Adams MG, Kelly PJ, Kodkany BS, Derman RJ. Postpartum hemorrhage in resource-poor settings. Int $J$ Gynaecol Obstet. 2006;92(3):202-211.
3. Knight M, Callaghan WM, Berg C, et al. Trends in postpartum hemorrhage in high resource countries: a review and recommendations from the International Postpartum Hemorrhage Collaborative Group. BMC Pregnancy Childbirth. 2009;9:55

4. Lazarus JV, Lalonde A. Reducing postpartum hemorrhage in Africa. Int J Gynaecol Obstet. 2005;88(1):89-90.

5. Munjanja S. Zimbabwe Maternal and Perinatal Mortality Study. Zimbabwe: Ministry of Health and Child Welfare/Unicef; 2007.

6. Ijaiya MA, Aboyeji AP, Abubakar D. Analysis of 348 consecutive cases of primary postpartum haemorrhage at a tertiary hospital in Nigeria. J Obstet Gynaecol. 2003;23(4):374-377.

7. Ononge S, Mirembe F, Wandabwa J, Campbell OM. Incidence and risk factors for postpartum hemorrhage in Uganda. Reprod Health. 2016; 13:38.

8. van Stralen G, von Schmidt Auf Altenstadt JF, Bloemenkamp KW, van Roosmalen J, Hukkelhoven CW. Increasing incidence of postpartum hemorrhage: the Dutch piece of the puzzle. Acta Obstet Gynaecol Scand. 2016;95(10):1104-1110. doi:10.101111/aogs.12950.

9. Miller S, Lester F, Hensleigh P. Prevention and treatment of postpartum hemorrhage: new advances for low-resource settings. J Midwifery Womens Health. 2004;49(4):283-292.

10. McCormick ML, Sanghvi HC, Kinzie B, McIntosh N. Preventing postpartum hemorrhage in low-resource settings. Int Gynaecol Obstet. 2002;77(3):267-275

11. Derman RJ, Kodkany BS, Goudar SS, et al. Oral misoprostol in preventing postpartum haemorrhage in resource-poor communities: a randomised controlled trial. Lancet. 2006;368(9543):1248-1253.

12. Prata N, Weidert K. Efficacy of misoprostol for the treatment of postpartum hemorrhage: current knowledge and implications for health care planning. Int J Womens Health. 2016;2016:341-349

13. Lalonde A, Daviss BA, Acosta A, Herschderfer K. Postpartum hemorrhage today: ICM/FIGO initiative 2004-2006. Int J Gynaecol Obstet. 2006;94(3):243-253

14. Walraven G, Wanyonyi S, Stones W. Management of postpartum hemorrhage in low-resource countries. Best Pract Res Clin Obstet Gynaecol. 2008;22(6):1013-1023.

15. Prata N, Bell S, Weidert K. Prevention of postpartum hemorrhage in low-resource settings: current perspectives. Int $J$ Womens Health. $2013 ; 5: 737-752$.
International Journal of Women's Health

\section{Publish your work in this journal}

The International Journal of Women's Health is an international, peerreviewed open-access journal publishing original research, reports, editorials, reviews and commentaries on all aspects of women's healthcare including gynecology, obstetrics, and breast cancer. The manuscript management system is completely online and includes

\section{Dovepress}

a very quick and fair peer-review system, which is all easy to use. Visit http://www.dovepress.com/testimonials.php to read real quotes from published authors. 